\title{
Significados e interacciones de paz de jóvenes integrantes del grupo "Juventud Activa" de Soacha, Colombia*
}

\author{
Meanings and Interactions of Peace in Members of the \\ "Active Youth" Group in Soacha, Colombia
}

Recibido: noviembre 9 de 2009 ～Revisado: septiembre 6 de 2010 ～Aceptado: diciembre 8 de 2010

\author{
Claudia Constanza Tovar Guerra** \\ STELLA SACIPA ${ }^{* * * *}$ \\ Pontificia Universidad Javeriana, Bogotá, Colombia
}

Para citar este artículo. Tovar, C. C., \& Sacipa, S. (2011). Significados e interacciones de paz de jóvenes integrantes del grupo "Juventud Activa" de Soacha, Colombia. Universitas Psychologica, 10(1), $35-46$.

* Artículo de investigación cualitativa.

** Facultad de Psicología, Cr. 5 \# 39-00 piso 2, Bogotá, Colombia.E-mail: claudia.tovar@javeriana.edu.co

** Facultad de Psicología, Cr. 5 \# 39-00 piso 2, Bogotá, Colombia. E-mail: ssacipa@javeriana.edu.co

RESUMEN

El artículo presenta y discute los resultados de la investigación que se desarrolló con la participación de jóvenes agrupados en la organización "Juventud activa”, orientados por una ONG que trabaja en el municipio de Soacha. Se estudiaron las similitudes y diferencias entre sus interacciones narradas acerca de su hacer cotidiano en el grupo, en la familia y en el barrio, en contraste con las formas en que significan la paz; empleando como método el análisis de narrativas. Los resultados mostraron consistencia entre interacciones narradas y significados, exceptuando algunos pocos casos. Se encontraron interacciones familiares ricas y diversas significadas positivamente por la mayoría de los jóvenes. La violencia es narrada en el contexto barrial, mientras que la paz es significada tanto en relación con esta violencia como con las interacciones armoniosas, en las cuales es evidente el papel del grupo "Juventud Activa".

Palabras claves autores

Significados, interacciones, paz, violencia, jóvenes.

Palabras claves descriptores

Adultos jóvenes, aspectos psicológicos, violencia, Psicología, paz.

\section{A B S T R A C T}

The article presents and discusses the results of a study carried out with the "Active Youth" group, which is guided by a NGO in Soacha, Colombia. The differences and similarities among their narrated interactions regarding their daily actions in the group, in the family and in the neighborhood were studied, in contrast to their meanings of peace and by means of narrative analysis. Except for a few cases, results showed consistency between narrated interactions and meanings. Rich and diverse family interactions, with positive meanings, were found. Violence is narrated in the neighborhood context, while peace is given meaning in terms of its relationship to this violence.

Key words authors

Young Adults, Psychological Aspects, Violence, Psychology, Peace.

Key words plus

Young Adults, Psychological Aspects, Violence, Psychology, Peace. 


\section{Introducción}

Altos de Cazucá es una comuna ubicada en la falda de una montaña, en el costado oriental del municipio de Soacha, en el departamento de Cundinamarca, en Colombia. El poblamiento de esta zona, como el de muchas zonas periféricas de las ciudades, ha sido desordenado y ha obedecido a la ola migratoria que la pobreza y el conflicto armado han ocasionado, desde hace más de cinco décadas en el país (Pérez, 2006).

Se trata de una zona marginal con condiciones de extrema pobreza. Fenómenos sociales tales como la violencia intrafamiliar, la venta y consumo abusivo de sustancias psicoactivas, la formación de pandillas y bandas criminales, que son frecuentes en sectores de pobreza, se amalgaman con la presencia del conflicto armado, generando un ambiente de violencia en el que la población juvenil, especialmente masculina, se constituye en principal víctima.

En medio de esta situación, los jóvenes están entre la falta de oportunidades hacia el futuro y el exterminio físico. Por fortuna, algunos jóvenes de la zona se vinculan a iniciativas alternativas, que organizaciones civiles les proponen, o ellos mismos crean grupos culturales, económicos o políticos, para generar nichos de paz y de oportunidades de formación y supervivencia.

Las investigadoras, a través del énfasis en acompañamiento psicosocial, han venido trabajando en algunas de estas iniciativas que la Fundación para la Educación y el Desarrollo (FEDES) ofrece a los jóvenes de las comunas más vulnerables de Soacha. El propósito de FEDES ha sido animar a los jóvenes a generar acción política desde la cotidianidad, a través de la formación en derechos, el arte y el juego. Propone que los jóvenes abran espacios de confianza y solidaridad en los cuales puedan dar curso no violento a su expresión, y busquen conjuntamente alternativas vitales para contrarrestar la amenaza permanente a la que están expuestos, por su condición de marginalidad. Durante el tiempo del acompañamiento y en concordancia con observaciones anteriores en investigaciones y experiencias similares con otras poblaciones, se ha evidenciado el desfase entre el decir y el hacer al interior de estas iniciativas (Sacipa, Cardozo, Ballesteros, Novoa \& Tovar, 2006).

Esto nos llevó a preguntarnos sobre las formas en que los jóvenes significan la paz y las maneras como narran sus interacciones en sus otros contextos como la familia, la escuela y el barrio. Una de las consecuencias importantes de este trabajo es reconocer hasta qué punto la participación en el grupo "Juventud Activa" marca la diferencia en su experiencia vital, con respecto a los otros contextos y, en esa medida, dilucidar claves para un trabajo psicosocial más efectivo.

Esta investigación se inscribe, en primer lugar, en los estudios de la Psicología de la Paz que Christie (2006) ha denominado de "construcción sistémica de la paz”, por cuanto exploran los contactos intergrupales, el manejo no violento de los conflictos y los movimientos hacia estructuras sociales justas. En segundo lugar, el estudio aborda el significado en la línea de Vigotsky (1973), como unidad del pensamiento verbal, como acto del pensamiento que se materializa en el habla y que se expresa en el concepto. Vigotsky plantea que la vida de una palabra es portadora de la vida de la cultura y que las prácticas lingüísticas se hacen vehículo de las relaciones sociales. En este sentido, consideramos que el análisis de los significados, posibilita un acercamiento a las maneras empleadas por las y los jóvenes, para construir explicaciones e interpretaciones acerca de la paz, a partir de su experiencia cotidiana.

La idea de la paz goza de una aparente adhesión universal, apareciendo en el horizonte de casi todas las aspiraciones humanas; no obstante, al indagar por los escenarios en que las personas imaginan esta paz materializada, aparecen las diferencias en su concepción. Por esto, es necesario establecer aquí cuál es la concepción que está en la base de esta investigación y que además de ser una toma de postura de las investigadoras, ilustra la comprensión de las maneras como los participantes del estudio la significan. En términos amplios, entendemos la paz en el sentido del llamamiento para la creación de un movimiento mundial para la cultura de paz y no violencia de la UNESCO, según la cual: 
La cultura de paz es la paz en acción. (...) Es una cultura de vida que consiste en permitir la convivencia de seres diferentes y en infundir una nueva ética de solidaridad, escucha, atención al prójimo y responsabilidad, en una sociedad democrática vigorizada que lucha contra la exclusión y garantiza la igualdad política, la equidad social y la diversidad cultural. $(1999$, p. 7$)$

Autores como Johan Galtung (2003), Vicent Fisas (1987) y Juan Pablo Lederach (2000), se han esforzado por analizar las tendencias históricas y culturales de Occidente, en la comprensión de la idea de paz, y las han contrastado con otras culturas para proponer un horizonte de entendimiento que sirva de brújula para que los pueblos emprendan el camino de construcción de la paz.

Para Galtung (2003), la paz supone condiciones de respeto mutuo, dignidad, igualdad y reciprocidad. Tanto este autor como Fisas (1987) consideran que la paz es la ausencia de todas las clases de violencia, directa, estructural y cultural, y constituye el contexto para que los conflictos sean transformados en forma creativa y no violenta. Por su parte, Lederach (2000) propone una idea desidealizada de la paz, al considerar el conflicto como inherente a las relaciones humanas, diferenciándolo de la violencia y atendiendo a los aspectos emocionales, cognitivos y comportamentales, en su transformación. En este mismo sentido, Galtung (2003) diferencia entre una cultura potencial de la paz que no ha incorporado y no ha configurado nuestras mentes, y una cultura real/actuada de la paz.

En este orden de ideas, la Psicología, desde diversas perspectivas, ha intentado aportar a la cultura actuada de la paz, identificando aquello que habría que promover en las maneras de pensar, sentir, actuar e interactuar de las personas, para abonar el terreno de su construcción. Así, la descentración social de Piaget (1999), la lectura en clave de culturas de paz de las prácticas de reciprocidad descritas por el análisis del comportamiento (Ballesteros, 2002), y los ya mencionados estudios de la psicología de la paz, superaron la idea psicologista - tan acorde con la idea de paz negativa - según la cual el ser humano es violento por naturaleza y la tarea de la paz no es otra que aplacar su nefasta tendencia. Estas nuevas perspectivas unidas a otras iniciativas interdisciplinarias (Arranz, 2008; Castañeda, Benítez, Tejada \& Bastidas, 2001; Pérez, 2006, entre otros) hacen un aporte a una idea positiva de la paz, intentando reconocer las maneras en que se construyen prácticas cotidianas susceptibles de ser formadas, en escenarios de educación y de acompañamiento concretos.

Con la idea de ser parte de este esfuerzo, en el presente estudio se acoge a la afirmación de Bruner (1995) según la cual "uno de los principales medios para mantener la paz consiste en presentar, dramatizar y explicar las circunstancias atenuantes que rodean las rupturas originadoras de conflictos en la vida ordinaria" (p. 97) y que "pertenecer a una cultura viable es estar ligado a un conjunto de historias interconectadas, aunque esta interconexión no suponga necesariamente un consenso" (p. 98). Por esta razón, se quiso convocar las narrativas de los jóvenes de Altos de Cazucá con los siguientes interrogantes: ¿cómo significan la paz? y icómo interactúan en sus diferentes contextos?

Así los objetivos propuestos fueron: reconocer los significados de paz en jóvenes, mujeres y hombres, habitantes de Altos de Cazucá; comprender las interacciones de los jóvenes en diversos contextos y sus significados, y analizar las convergencias y divergencias de los significados e interacciones de paz en las y los jóvenes.

\section{Método}

Se trata de un estudio fundamentado en el análisis de narrativas (Bruner, 1995), que permite leer los significados construidos por las personas, a través de lo que dicen sobre el mundo, sobre los otros y sobre sí mismos. En este sentido, se configura como un análisis psicocultural en el sentido en que lo define Serrano (1996), pues constituye “(...) un proceso interpretativo mediante el cual un investigador o grupo de investigadores, reconstruyen uno de los sentidos posibles de cualesquiera acciones y expresiones humanas significativas" (p. 103).

Teniendo en cuenta que, de acuerdo con la perspectiva históricocultural de la Psicología, tanto 
los estados intencionales como la acción se significan en el acto narrativo, se asumen las interacciones narradas como la vía para conocer la forma en que los jóvenes se encuentran con otros, en sus diferentes contextos: familiar, grupal, escolar y barrial.

\section{Instrumento}

Como instrumento de recolección de información y de encuentro con los participantes, se empleó la entrevista abierta y semiestructurada; de acuerdo con la propuesta de Bruner (1991) “(...) nuestro procedimiento para realizar las entrevistas [es] concebido para favorecer la creación de significados mediante el relato de narraciones" (p. 121); en consecuencia, está conformada por preguntas-guía abiertas, orientadas por los objetivos propuestos.

\section{Participantes}

Los participantes fueron seleccionados de manera intencional (Martínez, 1993), teniendo como criterio básico la pertenencia al grupo "Juventud Activa”. Se trabajó con seis jóvenes: cuatro hombres y dos mujeres, habitantes de Altos de Cazucá.

\section{Análisis de Resultados}

Las narraciones obtenidas en las seis entrevistas se organizaron en categorías emergentes, empleando como perspectiva de lectura la psicología de la paz.

\section{Análisis de las interacciones narradas en las entrevistas}

\section{Interacciones en la familia}

En las entrevistas a los jóvenes, se encontró que tres de ellos, narran interacciones familiares armoniosas. El joven (N1) cuenta: "nosotros todos los sábados y los domingos en la casa jugamos parqués,.. es chévere, es muy alegre en mi casa ...yo, a mi hermanita la trato bien, mi papá me ha dicho". La joven (N2) afirma: "me pongo a ayudarle a mi hermano a hacer tareas o a hacer canciones... en mi casa somos muy alegres, [nos reunimos] el 24 y 31 de diciembre y el 6 de reyes [se hace] el almuerzo todos en la familia y bailan ahí en mi casa". El joven (N3) narra: "es una relación muy bonita, somos muy unidos, mi papá tiene un negocio y a nosotros nos gusta mucho colaborar y respetarnos... yo casi no le digo padrastro le digo papá. Él me ha criado desde que yo tenía un año y me trata muy especialmente tengo tres hermanos y él me dice: mijo yo al que más quiero es a usted, porque usted fue el que me enseñó a ser papá. Mi mamá es tiene un trato diferente con uno, si con mi hermanito menor es tierna, con mi hermanito de la mitad es cariñosa, con mi hermanita es más sensible, son mujeres conmigo ya de mayor, ella confía más en mí por ser el más grande".

\section{Interacciones amistosas}

Los jóvenes entrevistados narraron interacciones de su articulación entre pares a través del juego y la fiesta. (N1): "los niños salen a jugar básquet o vamos ahí al frente jugamos" en armonía con los vecinos "ella juega mucho con todos nosotros ahí con todo el barrio". Interacciones en las que comparten actividades lúdicas: "con ellos algunas veces nos vamos en cicla... nos divertimos, vamos a jugar bola tranquilos". (N3): "nos gusta mucho hacer actividades en grupo... nos divertimos mucho. Jugamos fútbol, jugamos básquet, ahorita salió de moda los trompos, jugamos trompo". (N4): "salimos a jugar o vamos a bailar". Así como en el colegio, donde forman redes de amigos, (N1) cuenta: "mis compañeros lo buscan a uno para jugar"; y la joven (N2) relata: yo tengo hartas amigas, en el colegio nos hacemos llamar las 'maquiatoons', porque nosotras somos muy alegres". Con los amigos también se dan interacciones de cooperación. (N5): "uno necesite una tarea, o uno no entendió un tema, ellos le ayudan y viceversa".

Interacciones de inclusión y producción del diálogo

La mediación del reconocimiento, la conversación y el juego son situados, por tres de los entrevistados, en la base de las prácticas inclusivas. (N5): "reco- 
chamos, reírnos así, hablar de lo que vivimos, de todo de lo que hacemos en la semana, hablamos y nos damos a conocer". (N1): "Sería que hicieran las paces y se siguieran hablando a que vamos amigo que vamos lo invito a jugar que vamos a jugar...conseguimos unos amigos suyos... así se conforma claro, y hacen las paces, y se conforman entre todos, hablando, haciendo chistes, que se rían y juegos... y entonces ellos se van entrando mas al grupo".

Interacciones de carácter solidario, aроуо mutuo y cuidado

En la voz de dos de las entrevistadas se aprecian valores relativos a la solidaridad y el cuidado como conectores de vida comunitaria. (N2): "si allá falta un bocado de comida y en mi casa lo tenemos, pues entonces nosotros allá vamos, le damos, y si ella tiene y si nosotros no tenemos compartimos eso"; (N6): "ahí compartimos todo con todos". El joven (N3) narra interacciones a favor del cuidado de los más pequeños: "a los niños nos gusta cuidarlos mucho, digamos cuando vemos a una mamá golpeando al niño le decimos: 'oiga señora tenga más conciencia y la hacemos como reflexionar para que no hagan eso', aunque reporta cómo la respuesta de la madres, desalienta esta práctica de cuidado: "[nos dicen] que no seamos metidos, que no seamos sapos". También relata acciones conjuntas alrededor de la fiesta: "los vecinos son bastante unidos, cuando hay que representar el barrio se unen, por ejemplo ahora para hallowen, para las decoraciones de cada época, son muy unidos".

Interacciones que hablan de exclusión entre jóvenes

Las narraciones de tres entrevistados hablan de interacciones dialógicas con los que consideran más pares, cercanas con los vecinos y familiares, y lejanas con otros diferentes que habitan otros lugares, así todos formen parte del mismo grupo "Juventud Activa”. Refiriéndose a las interacciones entre ellos, la joven (N6) cuenta: "hay como dos grupos de personas porque no son como muy sociables y entonces pues siempre estamos separados y cada quien con su grupo....Por ejemplo los de Sibaté, los de Cazucá y nosotros los de Soacha. ...por lo que somos familiares y por lo que venimos de la misma parte"; y (N5): "hay un grupito que se tratan ahí entre ellos, nosotros somos como aparte ellos hacen su grupito allá y nosotros hacemos el grupito de nosotros". Mientras que uno de los jóvenes (N3) considerados como del otro grupo afirma: "lo que me disgusta, tal vez podría ser que las personas no participan, cuando estamos nosotros en la recocha y eso entonces, ellos no participan están fuera de la recocha".

Este tipo de interacciones de exclusión se dan también en el colegio tal como ellos lo cuentan. (N6): "[El muchacho] es como separado de todo el salón... no habla con nadie, se la montan por eso es que ellos... él se deja pegar", y el joven (N5) dice: "uno está hablando con ellos y se pasan, particularmente a mí eso no me gusta, por eso me trato más con los de mi edad, uno habla normal no tiene que ocultarse de nada y uno nunca se pasa". Encontramos así que aparece la tendencia a diferenciarse del otro, puntuando sus interacciones como "agresivas" y las propias como "normales no los de la mañana sí eran agresivos, los de la tarde no, normales" (N1).

\section{Análisis de significados}

Significados de la acción (justificaciones, legitimaciones, explicaciones)

Varios jóvenes justifican la violencia, como defensa y/o en función de la lealtad. (N1): "un chino cogió a un amigo enfermito y le golpeó y lo reventó, entonces yo fui y le di duro también lo reventé". (N4): "Hay chinos de otros barrios que son alzados uno no toca dejarse,... para uno defender a los amigos". Un joven explica la violencia de la calle mediada por normas de la zona que justifican el machismo que activa la violencia: "hay momentos en que uno no puede tolerar una cosa... en el momento en que se meten con la mamá de uno, a uno eso le duele mucho, ahí se arma la pelea... La política acá es que uno no se debe aguantar que otro se meta con 
la novia, que es de uno solamente y nadie más la puede mirar...”.

La responsabilidad en el ejercicio de la violencia se adjudica al grupo como mala influencia, el problema no es cómo estoy con otros, sino estar con otros. El joven (N4) dice: "si en veces uno mejor andar solo, sin armas solo... hay unos amigos que también lo copian a uno a malas cosas, que así como se meten en problemas se salgan también... allá no hay parches buenos, allá todo es el que más malo sea". Cuando este joven relata las consecuencias de la violencia que él ejerce, no muestra interés en el otro sobre quien ejerce la violencia: "[sentí] miedo, cuando yo miré el cuchillo untado de sangre, entonces yo le dije a mis amigos que nos fuéramos, que ese chino ya estaba herido [sentí miedo] de que el chino se muriera y yo no estaría aquí".

Otro joven le otorga a los actos violentos que ejercen "los de la limpieza", el carácter de justicieros; así dice: "ellos miran las personas que son malas, ellos ya las tienen grabadas, van y cuando hay una lista negra la pintan de rojo... lo buscan hasta matarlo, esa es la misión de ellos... hay un señor que hace respetar la cuadra" (N1).

\section{Significado Violencia Estructural}

El joven (N4), al significar la paz, hace un reclamo por la equidad: "como la por aquí también la gente es bien pobre [deben] ayudarle a hacer casas, también dar oportunidades de trabajo, estudio", y (N3) constata esta violencia: "en Cazucá hay mucha intolerancia... la violencia reina".

\section{Significado de la exclusión}

Tres jóvenes hablan de la exclusión como forma de relación a partir de la estigmatización: "hay unas chinas que piensan que saben más que uno, que ellas son las mejores, y todo el mundo es igual ino?" (N4); "los de Cazucá son muy groseros... como que no somos tan compañeras" (N6); "nosotros somos aparte, no somos como la mayoría que son todos gamines, somos pobres pero honrados" (N5).

\section{Significado paz negativa}

El joven (N5) entiende la paz como: "no más secuestros, no más violencia, no más pandillas, no asesinatos, no más peleas en los hogares, no más estafas, no más abusos de la clase alta, muchos abusan de la clase baja solo porque son pobres, eso sería la paz". Mientras que dos jóvenes reconocen un actor del conflicto: "que la guerrilla se entregara o se salieran" (N4); "que se acabaran los terroristas, que la guerrilla dejara de hacer secuestros, la paz total" (N1). El joven (N3), en contraste con los participantes anteriores, visualiza las partes en el conflicto: "hay muchas formas (de conseguir la paz), digamos para una pelea se necesita que hayan dos, si el gobierno retira sus ánimos de la guerra entonces las otras personas no van a tener con quien pelear, entonces en Colombia no se viviría la guerra".

\section{Significados de evitación}

Cuatro participantes refieren comportamientos de evitación de las confrontaciones: "por lo que allá es tan peligroso, hay más que refugiarse en la casa" (N6); "a mí me da miedo las peleas, al ver que estén peleando ... [hacer] de cuenta de que ni siquiera existen" (N2); "un grupito de amigos siempre forma cualquier pelea severa... tratando de huir las peleas, uno no se gana enemigos" (N5); "yo trato de ignorarlo, trato de no ponerle atención porque eso se presta para mas violencia" (N3). Este joven habla de cómo los padres evitan que sus hijos se expongan: "hay un muchacho en el barrio, sus papás no le permiten mucha calle, porque los chinos del barrio todos son dañados; los papás son los que lo enseñan a él a que no sea violento".

\section{Discusión}

Una amistad sana goza de características semejantes a las de las culturas de paz, por ello es estimulante encontrar en todos los contextos en los que se mueven los jóvenes, la presencia de lazos de amistad. Recordemos la analogía que hace Bustamante (2009): "La paz es un movimiento continuo, un ir 
haciendo camino, un aprender a convivir y resolver las cuestiones de la vida de manera equitativa para todos. La paz no se tiene, se mantiene. Es como una amistad que se cultiva" (p. 1).

Las formas de interacción que conectan la amistad entre las y los jóvenes, son similares en los diferentes espacios en que se mueven. Así, los jóvenes entrevistados narraron interacciones armónicas articuladoras, a través del juego y la fiesta entre pares y con los vecinos en el barrio. Se trata de interacciones amistosas basadas en el reconocimiento y mediadas por el juego (fútbol, microfútbol, básquet, trompo, ciclismo) como formas de diversión donde se estimula la amistad. De manera semejante sucede en el colegio - espacio en el que construyen redes sociales-, donde se hacen amigos especialmente con la mediación del juego y la cooperación en la actividad académica. La amistad fue observada en las interacciones del grupo "Juventud Activa", donde se expresaba como confianza, humor y goce, con intermediación del juego en las interacciones de los jóvenes, haciéndolas fluidas y expresivas.

Ahora bien, el juego no siempre conduce a relaciones de armonía entre los integrantes del grupo "Juventud Activa"; algunas de las interacciones que se inician como tal, derivan en pelea, especialmente en la interacción entre jóvenes hombres donde el jugueteo en ocasiones se acompaña con golpes. En estos jóvenes parecen encontrarse latentes las semillas de la ira y la violencia, que son susceptibles de crecer en el que creemos más inocente de los espacios. Por ello, consideramos importante retomar la idea de Arranz (2008), quien propone la enseñanza de los juegos de cooperación promotores de la convivencia y donde, como afirma $G$. Brown (citado por Arranz, 2008), a diferencia de los juegos de competencia, no se elimina a nadie. Los niños no juegan unos contra otros y todo el grupo gana cuando todas las niñas y niños colaboran mutuamente, puesto que de acuerdo a Romero y Gómez (2008 citado por Arranz, 2008) la idea madre de los juegos cooperativos es "jugar unos con otros y no unos contra otros".

La interacción lúdica permea, en algunas ocasiones, las interacciones en la familia, entre quienes viven en la misma casa; además del espacio lúdico, varios de ellos gozan de interacciones armónicas y de apoyo en la familia, basadas en el buen trato y la reciprocidad, mediadas por el reconocimiento, la unidad, el respeto, la empatía, la cercanía afectiva y la confianza. Las investigadoras consideraron que aún es necesario trabajar bastante en la construcción de culturas familiares de paz, pues solo la mitad de los participantes gozan de esta situación. Ahora bien, estas formas de interacción son semejantes a varias de las observadas en el grupo "Juventud Activa", donde una actitud lúdica, la mediación del reconocimiento, y la conversación son situadas, por los entrevistados, en la base de las prácticas inclusivas.

Para Ruiz Omeñaca y Omeñaca Cilla (2009), "Lo importante para quien juega es el juego mismo; la diversión, la alegría, la exploración de las propias posibilidades y la relación con los demás se mantienen para quienes participan en la actividad lúdica, al margen de definiciones y categorías" (p. 7). Jiménez (2001) plantea que la lúdica es una forma de estar en la vida y de relacionarse con ella en esos espacios cotidianos, donde se produce disfrute, goce, acompañados de la distensión que producen actividades simbólicas e imaginarias como el juego. Elaborando esta idea, Pérez (2006) propone que la lúdica se caracteriza "por rasgos tales como la creatividad, la espontaneidad, el optimismo y el buen sentido del humor, rasgos que afloran en las interacciones personales cotidianas, hacen que el sujeto tenga variadas perspectivas del mundo, facilitándole esto integrarse de diversas formas a la multiplicidad de espacios que socialmente se le presentan" (p. 42), lo que en nuestra perspectiva, la convierte en una característica que puede ser facilitadora de la construcción de culturas de paz.

Ballesteros, Novoa y Sacipa (2009) reportaron la falta de correspondencia entre las expresiones relativas a la concepción política de paz y las prácticas cotidiana de jóvenes estudiantes de secundaria. De otra parte, las autoras ya habían señalado esta dificultad en una investigación previa (Sacipa, Cardozo \& Tovar, 2005). Ahora bien, en el estudio actual encontraron mayor consistencia de la esperada entre interacciones narradas, observadas 
y construcción de significados; en particular, en los casos de jóvenes que son consistentemente pacíficos. Es probable que la diferencia radique en la pertenencia de los participantes al grupo "Juventud Activa" que promueve el buen trato y/o a la influencia familiar, ya que se encontraron varias familias que promueven la interacción amorosa. La disposición amorosa a promover la paz y el reconocimiento del hogar como el lugar primario para iniciar un cambio, ya se habían reportado en los estudios anteriormente nombrados. Sin embargo, se observó incongruencia en un joven y una joven. En particular para el joven, no es visible la conciencia de la relación entre el actuar propio, la forma de significar la paz y la posibilidad de construirla, dado que algunos meses después de cometer un acto muy violento y narrando aún interacciones violentas, dice que la paz consiste en "que nadie mate a nadie".

La filósofa Román (2008) hace énfasis en la diferencia entre la identidad individual y la colectiva, y el error que se comete al no tener en cuenta este segundo concepto: se olvida de que no hay individualidad de persona si no es dentro de un grupo. En varios jóvenes se verificó, muy claramente, el papel de la identidad colectiva que los lleva a interactuar de maneras diferentes, según los grupos en que se encuentren, de manera que en unos contextos las interacciones se caracterizan por ser de ayuda mutua y respeto, en tanto que en otros, las transforman tomando matices de evitación. Más aún, algunos de ellos comparten en sus grupos de referencia lo que la autora llama "identidades negativas", donde se tornan excluyentes e incluso agresivos. Esto llama aún más la atención, al contrastar las interacciones narradas con los significados de paz expresados por ellas y ellos tales como "vivir todos en comunidad", "saber convivir y que haya mucho respeto".

Galtung (1996) y Fisas (1998) afirman que el planteamiento de la paz negativa implica la ausencia de violencia directa, incluyendo las referencias a la paz como la ausencia de conflicto o cese de hostilidades. Ahora bien, todos los jóvenes participantes en la investigación significan su comprensión de la paz en estos términos, aunque algunos de ellos proponen algunos matices a la misma. Entre quienes consideran que la paz es el fin de la guerra se encuentran dos jóvenes que reconocen solo un actor del conflicto al que le asignan la responsabilidad de la ausencia de paz, y consideran que debe abandonar el terreno o entregarse; uno de ellos extiende este concepto a las pandillas de su contexto barrial, desconociendo los otros actores que participan en el conflicto armado. Ahora bien, la forma en que estos jóvenes significan la paz nos habla de la violencia cultural que legitima la violencia estructural y física como lo plantea Galtung (1996 citado por Dietrich, s.f.). Otro joven, aunque identifica la paz como cese de hostilidades, en contraste con los participantes anteriores, visualiza las partes en el conflicto armado y le pide al Gobierno retirar sus ánimos de guerra, hablando desde una postura no polarizada. Una visión de más complejidad que incluye tanto el cese de la violencia directa como el de la violencia estructural, planteada por Galtung (1971), es la de un joven que entiende la paz en términos de paz negativa y de paz positiva.

En un estudio elaborado hace cuatro años (Sacipa et al., 2006), las autoras del presente estudio encontraron que los ciudadanos significaron la paz como evitación de los conflictos, donde se incluían expresiones relativas a patrones de conducta caracterizados por la evitación social de las dificultades en las interacciones con personas o grupos. Varios participantes en esta investigación refirieron comportamientos de evitación de las confrontaciones, en especial en su cotidianidad de la vida del barrio, lo que se caracteriza como una estrategia empleada, con frecuencia, por las familias de los jóvenes, consistente en alejar a los hijos de la calle y de los otros jóvenes de la zona, guiados ya sea por la idea de la influencia negativa que estos ejercen o por la idea de impedirles cualquier contacto con las pandillas u otros actores armados y evitar, así, cualquier tipo de conflicto. En las narraciones, varios jóvenes hacen explícita la internalización del la evitación, incluso en las interacciones más cercanas y proponen como alternativa centrarse en el estudio, pues consideran que esta los salvaguarda de las interacciones violentas. 
Fisas (1987) considera que la paz, en sentido amplio, supone la ausencia de violencia directa y estructural; ello implica generar bienestar, satisfacción de las necesidades humanas básicas, identidad y libertad para todos. En este sentido, un joven participante en la investigación entiende la paz como el cese de la violencia directa y de la violencia estructural. Martínez Rodríguez (2006) nos recuerda que, en general, la violencia es toda aquella situación conflictiva que no ha sabido resolverse y canalizarse de manera satisfactoria perjudicando a alguna de las partes implicadas y cita a Galtung (1985, p. 76) quien la define como "algo evitable que obstaculiza la autorrealización humana”. En ese orden de ideas, un joven hace un reclamo por la equidad a partir del reconocimiento de la violencia estructural, declarando que la paz implicaría darles vivienda, trabajo y educación a los habitantes del barrio. Sin embargo, desde este reconocimiento y el de la violencia directa en su barrio, al narrar: "en veces la guerrilla o los paracos va a reclutar a los chinos, de por acá que no tienen oportunidades", incluso él parece tomar una opción por las armas, a partir de los sentimientos de ira por la violencia estructural: "yo lo pensaría, en veces también a uno le da rabia, que uno quisiera irse".

Sin embargo, llama la atención de las investigadoras que la mayoría de los participantes no hablan del tema estructural, en contraste con investigaciones anteriores adelantadas donde también se exploraron los significados de paz (Sacipa et al., 2005; Sacipa et al., 2006), en las cuales para la mayoría de los grupos estudiados la paz se significa en relación con la satisfacción de necesidades básicas, el equilibrio socioeconómico, el acceso a la salud, a la educación, a la vivienda y al empleo para todos los integrantes de la sociedad, en sintonía con Galtung (1998) y Fisas (1998) quienes conciben la paz estructural, como condiciones de la estructura social que permiten el libre desarrollo de los miembros de la comunidad y, por tanto, propenden por la dignidad humana.

De igual manera, otro estudio reciente (Ballesteros et al., 2009) mostró la preocupación de los jóvenes estudiantes de secundaria por la debilidad del Estado para generar equidad y justicia social.
De manera que la postura de los participantes que no visibilizan el problema estructural, nos habla del papel de los actores armados que tiende a normalizar la expresión y silenciar la protesta..

Como lo han señalado diversos autores (Fisas, 1987; Galtung, 2003; Lederach, 2000), la idea de la paz goza casi de un consenso social. Pero esta idea de paz acogida ampliamente, es una abstracción que encuentra sus diversas manifestaciones a la hora de especificar las condiciones y los escenarios en los que cada quien imagina su materialización. Es frecuente, por ejemplo, que el común de la gente en los países de influencia occidental, haga estas especificaciones aludiendo, por contraposición o como camino, al ejercicio de la violencia y que resulte más fácil describir esa violencia que un escenario de paz como tal. Como ya vimos, los resultados de esta investigación muestran, una vez más, esta tendencia. Los participantes, antes de reconocer condiciones positivas para la paz, hablan de paz como ausencia o supresión de violencia y, en otros casos, ausencia de conflictos, lo que resulta más inquietante.

Esta alusión muchas veces está matizada por la legitimación del ejercicio de la violencia. Así, se considera que la paz pasa por el cese de las hostilidades, pero para que esto ocurra, contemplan la hostilidad misma como instrumento. De esta forma, vale la violencia para defender a la mamá, a la novia o a un compañero más débil; vale como acto de venganza y para ganarse el "respeto" de un agresor; vale para mostrar lealtad a los amigos y vale cuando la provocación sobrepasa ciertos límites. En este sentido, la legitimación de la violencia, a la hora de entender la paz, opera como una violencia con reglas ("política cazuqueña", por ejemplo) que se considera como un mal necesario en el logro de la paz. La idea de paz que aquí subyace es la de pax romana analizada por Lederach (2000)), que hace referencia al orden y al aplacamiento de los conflictos a partir del parámetro de la ley o, en su defecto, de lo que se considera legítimo en una sociedad dada. Este aplacamiento no excluye, claro está, el uso de la violencia.

En esta idea de paz, las consideraciones sobre los intereses de las partes de los conflictos y los 
componentes afectivos de las relaciones, pasan a un segundo plano o desaparecen. La idea de bien, tiene una tácita alusión al "bien común”, en la más radical de sus formas, que subsume la experiencia singular de cada persona a la unidad colectiva. Esta concepción explica la naturalización de las prácticas represivas, en particular de la limpieza social, que los jóvenes muestran tanto en sus significados como en sus interacciones narradas.

Una concepción de paz como ésta, facilita la construcción de maneras maniqueas de ver la realidad social, que encuentran un eco fascinante en los discursos políticos de oferta heterónoma de paz y orden. Así, existen los buenos, identificados con ese bien común, es decir el pueblo, los ciudadanos de bien, los colombianos (o el sustantivo de turno más convincente) y existen los malos (terroristas, subversivos, etc.) identificados con todo aquello que atente contra la tranquilidad de los primeros.

En el afán de identificarse con los buenos, que constituye una tendencia cultural bien documentada, y que los psicólogos sociales de la escuela clásica han descrito como un impulso por disminuir las incómodas disonancias cognitivas (Festinger, 1957) que las contradicciones, complejidades y paradojas provocan. Se puede decir que, motivados por estas disonancias, los miembros de una sociedad construyen maneras discursivas de diferenciarse de los malos y de explicar las propias interacciones como distintas de las de éstos.

En los conflictos, el o los adversarios encarnan esta idea del mal y son el parámetro palpable de esta manera negativa de construir la idea de sí mismo. De esta manera, los participantes de este estudio han construido la justificación de sus propias acciones violentas y han consolidado estereotipos y prejuicios sobre otros jóvenes (de otros barrios, de otros grupos, incluso de otro subgrupo de su propio grupo). En las interacciones narradas tales ideas toman la forma de la exclusión y la discriminación.

Así, también es posible comprender el camino de la conversión "del otro malo en uno de nosotros, los buenos", que aparece en las narraciones de los jóvenes entrevistados. Esta es una idea que se refuerza en las propuestas educativas homogeni- zantes y en las ofertas militarizadas de participación en la guerra.

En términos de paz, la idea de Jean Piaget ${ }^{1}$ de que el núcleo de una educación para la paz es la comprensión del otro en tanto diferente y a la vez interdependiente de uno mismo, nos alerta acerca de que esta dinámica de identidad negativa, de evidente cariz egocéntrico, debe ser movilizada hacia una descentración social que facilite a los jóvenes la búsqueda de referentes positivos de identidad y de significados complejos sobre el valor de la diversidad.

Algunos de los entrevistados, cuando hacen el ejercicio de reconocer la paz en sus interacciones cotidianas, se acercan a una idea de paz como orden social, salen rápidamente de las formas lineales y maniqueas de entenderla y encuentran en su experiencia -especialmente la que está mediada por una afectividad positiva - elementos de comprensión de la paz esperanzadores. En ambientes como la familia y el grupo organizado del que participan, pueden reconocer la reciprocidad positiva en sus interacciones. Así, aparecen elementos como el autocontrol a manera de herramienta para aplazar y transformar una reacción violenta a una provocación, o la valoración de la flexibilidad y la capacidad para perdonar como maneras de desescalar el ciclo de reproducción de la violencia (Ballesteros de Valderrama, 2002). Por primera vez, aparece aquí una mirada del conflicto diferenciado de la violencia, como lo propone Lederach (2000).

En este mismo sentido, una de las jóvenes entrevistadas refleja la ya mencionada descentración social, al entender al otro en su diferencia, como un humano semejante: “...si somos personas ipor qué tenemos que hacerle daño a otra persona?" lo que le permite identificar el espiral vicioso de la violencia: “... si ellos le hicieran daño a otro

1 Reconocido espistemólogo y fundador de la escuela del Constructivismo Genético, trabajó y llegó a dirigir, durante varias décadas, la Oficina Internacional de Educación en el Instituto Jean-Jacques Rousseau de Ginebra (Suiza), cuyo propósito principal era promover la paz y la comprensión internacionales mediante la educación. Estando allí, escribió varios textos dedicados al tema de la Educación para la Paz y la Colaboración Internacional. 
persona, digamos a la familia de la persona que le hizo ese daño, ellos van a tener mucha rabia...".

La alusión a los valores para hablar sobre la paz, orienta en la comprensión de sus significados. Así, los jóvenes aludieron al respeto (entendido como no traspasar determinados límites), a la unión, a la solidaridad y el cuidado mutuo. Papacchini (1998) considera que los valores son producto de la praxis humana y de la historia, más que esencias eternas transituacionales; estos contribuyen a consolidar relaciones humanas y a enriquecer y potenciar la vida individual y social. Los cuatro valores mencionados por los participantes revelan un fuerte sentido relacional del significado de paz, contrastante con los significados en otras poblaciones (Sacipa et al., 2006), como estudiantes universitarios, amas de casa y ejecutivos, cuyas concepciones de paz aparecen predominantemente en el plano individual, asociadas a valores como la tranquilidad espiritual, el amor y al buen trato unilateral y vertical (hacia el hijo, el empleado, el pobre).

En conclusión, la investigación pone en evidencia la existencia de semillas para construir culturas de paz basadas en la manera como significan y viven la amistad y la lúdica. Para este propósito el grupo "Juventud Activa" representa para los jóvenes espacio de contención amorosa. En contraste con la oferta de la institución educativa, que suele limitarse al discurso sobre el diálogo sin ponerlo en práctica, este grupo construye un ambiente de resistencia a las prácticas violentas y promueve interacciones congruentes con lo que entendemos como culturas de paz.

Por fortuna, algunas familias mantienen una actitud lúdica en sus maneras de vincularse e interactuar en su seno. En un contexto barrial tan adverso y de alto riesgo, ello constituye una manera de resguardarse frente a esta violencia. En síntesis, existen condiciones que abonan el terreno para la construcción de culturas de paz en medio de condiciones de violencia estructural y directa.

\section{Referencias}

Arranz, E. (2008). Metodología didáctica para la práctica de los juegos cooperativos en el ámbito escolar.
Disponible en http://www.educarueca.org/spip. php?article 574

Ballesteros de Valderrama, B. P. (2002). La realidad colombiana desde el análisis del comportamiento: paz, resultado de prácticas culturales. Universitas Psychologica, 1 (1), 81-91.

Ballesteros, B., Novoa, M. \& Sacipa, S. (2009). Prácticas culturales de paz en jóvenes adscritos y no adscritos a la red de jóvenes por la paz. Universitas Psychologica, 8 (3), 613-624.

Bustamante, J. (2009, diciembre). Creando paz. En Carta de la Paz dirigida a la ONU. Recuperado el 3 diciembre, 2009, de http://www.cartadelapaz.org/ portal_cp/ecpau_detall.php?id $=900$

Bruner, J. (1995). Actos de significado (2 ed.). Madrid: Alianza.

Castañeda, R., Benítez, D., Tejada, C. \& Bastidas, A. (2001). Desarrollo de habilidades para la paz. Bogotá: Programa por la paz de la Compañía de Jesús.

Christie, D. (2006). What is Peace Psychology the Psychology of? Journal of Social Issues, 62 (1), 1-17.

Dietrich, W. (s.f.). La paz: sobre la dificil historia de un concepto clave de la cultura. UNESCO Chair for Peace Studies Virtual Peace Library. Recuperado 9 de diciembre, 2009 de http://www.uibk.ac.at/ peacestudies/downloads/peacelibrary/

Festinger, L. (1957). A theory of cognitive dissonance. Stanford, CA: Stanford University Press.

Fisas, V. (1987). Introducción al estudio de la paz y de los conflictos. Barcelona: Lerna.

Fisas, V. (1998). El sexo de la violencia: género y cultura de la violencia. Barcelona: Icaria.

Galtung, J. (1971). A Structural Theory of Imperialism. Journal of Peace Research, 8 (2), 81-117.

Galtung, J. (1985). Sobre la paz. Barcelona: Fontamara.

Galtung, J. (1996). Peace and peaceful means: Peace and conflict, development and civilization. Oslo: International Peace Research Institute.

Galtung. J. (1998). Actores constructores de paz. En iEs posible la Paz en Colombia? Tendencias Recientes en la Investigación Mundial sobre Paz y Conflictos. Bogotá: ESAP.

Galtung, J. (2003). What is a culture of peace and what are the obstacles? Consultado el 14 de mayo, 2007, en http://www.transcend.org 
Jiménez, C. (2001). La lúdica como experiencia cultural. Etnografía y hermenéutica del juego. Bogotá: Cooperativa Editorial Magisterio.

Lederach, J. (2000). El abecé de la paz y los conflictos. Educación para la paz. Madrid: Catarata.

Martínez, M. (1993). La etnografía como alternativa de investigación científica. Conferencia preparada para el Simposio Internacional de Investigación Científica, Santa fe de Bogotá, Colombia.

Martínez Rodríguez, (2006). Globalización, violencia estructural y pobreza. V Congreso Internacional Educación y Sociedad, Facultad de Educación, Universidad Granada, España. Disponible en http://congreso.codoli.org/area_1/Martinez-Rodriguez.pdf

Papacchini, A. (1998). Un mapa orientativo acerca de los valores éticos de la modernidad. Revista UISHumanidades, 27 (1), 25-42.

Pérez, A. (2006). La lúdica: una estrategia que favorece el aprendizaje y la convivencia. Proyecto Cazucá. Jardín Infantil Madre Clara Fey. Bogotá: Fundación Universitaria Monserrate.

Román, B. (2008). Modelos de Identidad. Intervención en Carta de la Paz. Disponible en http://www.cartadelapaz.org/portal_cp/eagora
Ruiz Omeñaca, J. \& Omeñaca Cilla, R. (2009). Juegos cooperativos y educación física. Buenos Aires: Paidós.

Sacipa, S., Ballesteros, B. P, Novoa, M., Cardozo, J. \& Tovar, C. (2006). Understanding peace through the lens of Colombian youth and adults. Peace and Conflict: The Journal of Peace Psychology, 12 (2), 157-174.

Sacipa, S., Cardozo, J. \& Tovar, C. (2005). Las y los ciudadanos de Bogotá significan la paz. Universitas Psychologica, 4 (1), 97-106.

Serrano, J. (1996). La psicología cultural como psicología crítico-interpretativa. En A. Gordon \& J. Linaza (Eds.), Psicología, discursos y poder (PDP) (pp. 93-106). Madrid: Aprendizaje Visor.

Organización de las Naciones Unidas para la Educación, la Ciencia y la Cultura. (1997). Movimiento mundial para la cultura de paz y no violencia. Quito: UNESCO.

Vigotsky, L. S. (1973). Pensamiento y lenguaje teoría del desarrollo cultural de las funciones psíquicas. Buenos Aires: Pléyade. 